\title{
Improving the Hydrophobicity of ZnO by PTFE Incorporation
}

\author{
Meenu Srivastava, Bharathi Bai J. Basu, and K. S. Rajam \\ Council of Scientific and Industrial Research, Surface Engineering Division, National Aerospace Laboratories, \\ Bangalore 560 017, India \\ Correspondence should be addressed to Meenu Srivastava, meenu_srivas@yahoo.co.uk
}

Received 7 March 2011; Accepted 24 March 2011

Academic Editor: Mallikarjuna Nadagouda

Copyright (C) 2011 Meenu Srivastava et al. This is an open access article distributed under the Creative Commons Attribution License, which permits unrestricted use, distribution, and reproduction in any medium, provided the original work is properly cited.

\begin{abstract}
The objective of the present study is to obtain a zinc oxide- ( $\mathrm{ZnO}-$ ) based superhydrophobic surface in a simple and cost-effective manner. Chemical immersion deposition being simple and economical has been adopted to develop modified ZnO coating on glass substrate. Several modifications of $\mathrm{ZnO}$ like treatment with alkanoic acid (stearic acid) and fluoroalkylsilane to tune the surface wettability (hydrophobicity) were attempted. The effect of thermal treatment on the hydrophobic performance was also studied. It was observed that thermal treatment at $70^{\circ} \mathrm{C}$ for $16 \mathrm{hrs}$ followed by immersion in stearic acid resulted in high water contact angle (WCA), that is, a superhydrophobic surface. Thus, a modified $\mathrm{ZnO}$ superhydrophobic surface involves the consumption of large amount of electrical energy and time. Hence, the alternate involved the incorporation of low surface energy fluoropolymer polytetrafluoroethylene (PTFE) in the ZnO coating. The immersion deposited ZnO-PTFE composite coating on modification with either stearic acid or fluoroalkylsilane resulted in a better superhydrophobic surface. The coatings were characterized using Scanning Electron Microscope (SEM) for the surface morphology. It was found that microstructure of the coating was influenced by the additives employed. A flower-like morphology comprising of needle-like structure arranged in a radial manner was exhibited by the superhydrophobic coating.
\end{abstract}

\section{Introduction}

Superhydrophobic surfaces (water contact angle $>150^{\circ}$ ) are gaining importance in industrial applications and academia due to their unique properties like self-cleaning, deicing, antisticking, and anticontamination. Some of the applications include self-cleaning paints, transparent antireflective coatings, self-cleaning glass, and wiperless windshields. In recent times, their usage in aerospace sector is also being explored, particularly in the tail and wings of the aircraft to reduce drag and thereby improve the efficiency of the engine. Superhydrophobicity can be achieved by obtaining a surface of micro- to nanoscale architecture [1]. Empirical models have been proposed on the basis of experimental data to explain the surface wetting properties and to understand the phenomenon of superhydrophobicity. Interest in this phenomenon increased in 1997 when the origin and the universal principle of "Lotus Effect" in nature were explained by Zhang et al. [1]. Since then, research has been focused on mimicking nature and trying to fabricate such surfaces artificially.
Various methods have been recommended for the fabrication of such a surface. Broadly, they have been classified as top-down approach, bottom-up approach, and a combined approach. Solution immersion process, which is a bottomup method, has been adopted in the present study. The advantage of this method is that it is simple, economical and can be easily scaled up for large area applications. $\mathrm{ZnO}$ has been chosen because of its antimicrobial property, easy availability, and nontoxic nature [2]. Also it has other properties like photocatalytic ability, electrical conductivity, UV absorption, and photo-oxidizing capacity for chemical and biological species. Very recently, preparation of cotton bandages with antibacterial properties by immobilizing $\mathrm{ZnO}$ nanoparticles on the fabric surface has been reported [3]. Considerable work has been carried out on the immersion deposition of $\mathrm{ZnO}$ [4-12]. Shinde et al. have reported the structure, optical and electrical properties of heat-treated $\mathrm{ZnO}$ [4]. Similar aspect of Sr-doped $\mathrm{ZnO}$ film has also been studied [5]. The effect of thermal desorption of stearic acid on the superhydrophobic performance of $\mathrm{ZnO}$ has been reported by Saleema and Farzaneh [6]. ZnO nanorods have 
been synthesized by chemical route by some investigators [7]. Yin and Sato have reported novel superstructures of $\mathrm{ZnO}$, namely, nanoscrew and nanodisk obtained from the solution route [8]. Other modified superhydrophobic surfaces based on $\mathrm{Cu}, \mathrm{Ag}$, $\mathrm{Co}$, Ni created through solution immersion process have also been reported [13-17]. In the present study, solution immersion deposited $\mathrm{ZnO}$ coating has been subjected to different modifications like heat treatment, immersion in alkanoic acid (stearic acid), combination of heat treatment and immersion in alkanoic acid, and immersion in fluoroalkylsilane. Stearic acid had been adopted as Wu et al. had reported that octadecanoic acid (C18 acid, stearic acid) imparted higher hydrophobicity compared to other acids of different chain lengths [9]. The influence of polytetrafluoroethylene (PTFE) on the hydrophobic nature was also studied by preparing $\mathrm{ZnO}$ PTFE composite coating by immersion route. PTFE was chosen as it is a fluoropolymer with very low surface energy. The water contact angle of smooth PTFE film is about $108^{\circ}$, and by the axial extension of the crystals the water contact angle increases beyond $150^{\circ}$ [18]. The PTFE-based coatings were also modified with alkanoic acid and fluoroalkylsilane. Thus, in this study, the investigators have attempted to improve the superhydrophobic behaviour of $\mathrm{ZnO}$ by PTFE incorporation, and a comparison with modified $\mathrm{ZnO}$ in terms of their microstructure and wettability behaviour has been made.

\section{Materials and Methodology}

$\mathrm{ZnO}$ was deposited on a glass substrate by immersion in a solution containing $30 \mathrm{~g} \mathrm{~L}^{-1}$ zinc nitrate hexahydrate and $53.3 \mathrm{~mL} \mathrm{~L}^{-1}$ ammonium hydroxide solution (25\%). The chemical etching of the substrate was carried out to induce surface roughness. Surface roughness plays an important role in determining the wetting behaviour of solid surfaces [19]. The etchant and etching time was standardized. $\mathrm{HF}: \mathrm{HNO}_{3}$ mixture in the ratio $1: 3$ for a duration of $3 \mathrm{sec}$ was adopted to obtain uniform $\mathrm{ZnO}$ coating on glass. The immersion time and temperature were also standardized. Deposition temperature of $70^{\circ} \mathrm{C}$ and an immersion time of $2 \mathrm{~h}$ after initiation of precipitate formation were employed. The asprepared $\mathrm{ZnO}$ coatings were subjected to modifications such as heat treatment at $350^{\circ} \mathrm{C}$ (for $2 \mathrm{~h}$ and $4 \mathrm{~h}$ ) and immersion in alkanoic acid-octadecanoic acid (stearic acid). The various concentrations of the acid solution in acetone used were $0.002 \mathrm{M}, 0.01 \mathrm{M}, 0.06 \mathrm{M}$, and $0.10 \mathrm{M}$. The other modifications included heating of $\mathrm{ZnO}$ coating at $70^{\circ} \mathrm{C}$ for $16 \mathrm{~h}$ followed by immersion in alkanoic acid and modification of the coating by immersion in fluoroalkylsilane, $1 \mathrm{wt} \%$ FAS- 17 solution in ethanol for $1 \mathrm{~h}$. The modified coatings were dried under ambient conditions.

The ZnO-PTFE composite coatings were deposited by dispersing the PTFE $\left(10 \mathrm{~mL} \mathrm{~L}^{-1}\right)$ emulsion in the zinc nitrate solution, and the deposition was performed under similar conditions as that of $\mathrm{ZnO}$. The composite coating was modified by immersion in $0.002 \mathrm{M}$ stearic acid solution in acetone for $1 \mathrm{~h}$ and fluoroalkylsilane in ethanol for $1 \mathrm{~h}$. These modified coatings were characterized for their surface morphology and wetting behavior, and a comparison with modified $\mathrm{ZnO}$ has been made.

Static water contact angles (WCAs) of the coatings were measured using contact angle analyzer, model Phoenix 300 Plus from M/s Surface Electro Optics, Republic of Korea. Tangent fitting mode is used in this instrument for the determination of WCA. The drop volume was $8 \mu \mathrm{L}$ in this study. WCA is influenced by volume of water droplet and gravity force. Hence, WCA must be measured with the same volume of water droplet. Also, the same fitting method must be used for calculating WCA while comparing superhydrophobicity of different surfaces as explained by Zhang et al. [1]. They found that WCA values from $156^{\circ}$ to $179^{\circ}$ could be obtained for the same water droplet on a surface depending on different fitting modes such as ellipse fitting, circle fitting, tangent searching, or LaplaceYoung fitting. Five measurements of WCA on the coating were taken, and the mean value was reported. The crystalline structure of the coatings was examined by X-ray diffraction (XRD) technique, Model Rigaku D/max 2200 powder diffractometer, using $\mathrm{CuK}_{\alpha}$ radiation of wavelength $0.154 \mathrm{~nm}$. The diffraction patterns were scanned between $20^{\circ}$ and $100^{\circ}$ in steps of $0.02^{\circ}$ at $2 \mathrm{deg} \mathrm{min}^{-1}$ scan speed. The surface morphology of the coatings was studied using a scanning electron microscope, SEM Model LEO 440I.

\section{Results and Discussion}

3.1. Microstructure and Hydrophobicity of Modified $\mathrm{ZnO}$ Coatings. X-ray diffraction patterns of as-deposited $\mathrm{ZnO}$ coating and modified $\mathrm{ZnO}$ coating are shown in Figure 1. The diffraction peaks in Figure 1(a) indicate the presence of major amounts of $\mathrm{ZnO}$ with hexagonal wurtzite structure and smaller amounts of zinc hydroxide, $\mathrm{Zn}(\mathrm{OH})_{2}$. No other characteristic peak was observed for other impurities, and all the peaks are narrow indicating higher crystallinity. The probable reaction mechanism is

$$
\begin{gathered}
\mathrm{Zn} \longrightarrow \mathrm{Zn}^{2+}+2 \mathrm{e}^{-} \\
\mathrm{O}_{2}+4 \mathrm{e}^{-}+2 \mathrm{H}_{2} \mathrm{O} \longrightarrow 4 \mathrm{OH}^{-} \\
\mathrm{Zn}^{2+}+2 \mathrm{OH}^{-} \longrightarrow \mathrm{Zn}(\mathrm{OH})_{2} \longrightarrow \mathrm{ZnO}+\mathrm{H}_{2} \mathrm{O}
\end{gathered}
$$

Zinc gets oxidized forming zinc cations (1), and oxygen gets reduced producing hydroxyl ions (2). These hydroxyl anions react with zinc cations to form zinc hydroxide (reaction (2)) which under slightly acidic condition transforms to the stable $\mathrm{ZnO}$ that is insoluble and appears as white precipitate on the surface [19]. This mechanism can be correlated with the presence of $\mathrm{ZnO}$ and $\mathrm{Zn}(\mathrm{OH})_{2}$ in the diffractogram.

Surface morphology of various modified $\mathrm{ZnO}$ coatings is shown in Figure 2. It can be seen from Figure 2(a) that the morphology of as-deposited $\mathrm{ZnO}$ coating consists of uniform flower-like pattern. Every flower-like structure is composed of many rods with a sharp tip, and these rods are aligned in a radial pattern from the centre. The growth mechanism can be interpreted as an epitaxial growth wherein the $\mathrm{ZnO}$ nuclei initially formed a seed layer. The ammonium ions adsorbed on the surface of the $\mathrm{ZnO}$ nuclei promoted 


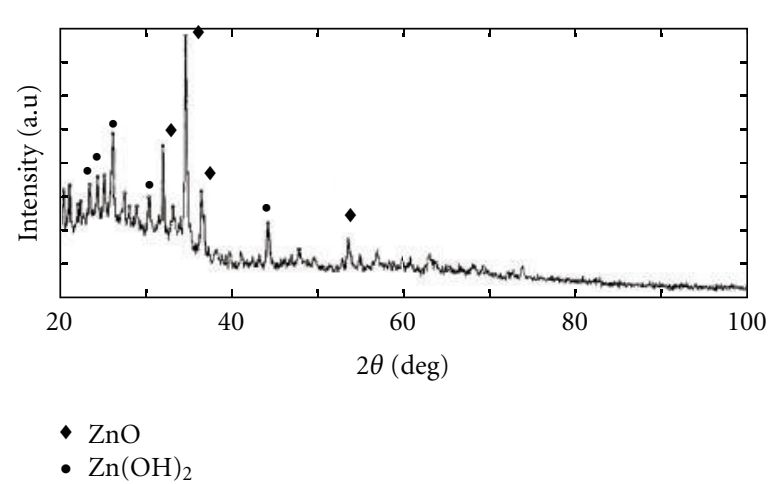

(a)

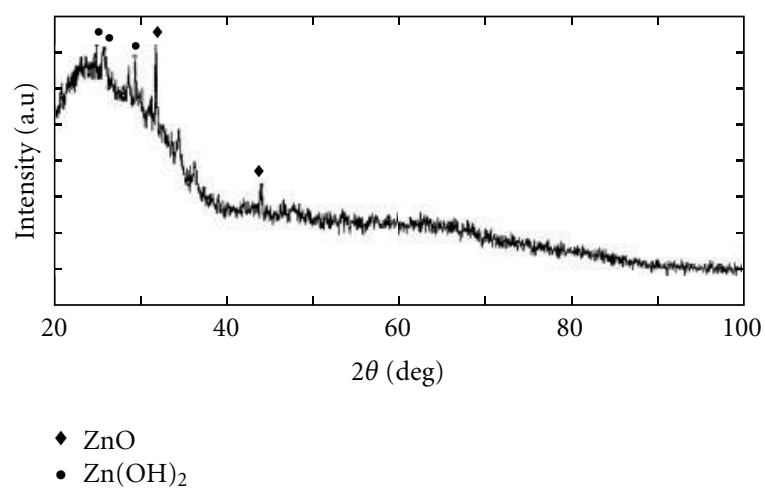

(b)

Figure 1: X-ray diffractograms of (a) as-deposited $\mathrm{ZnO}$ coating and (b) $\mathrm{ZnO}$ coating heat treated at $70^{\circ} \mathrm{C}$ and immersed in stearic acid $(0.002 \mathrm{M})$.

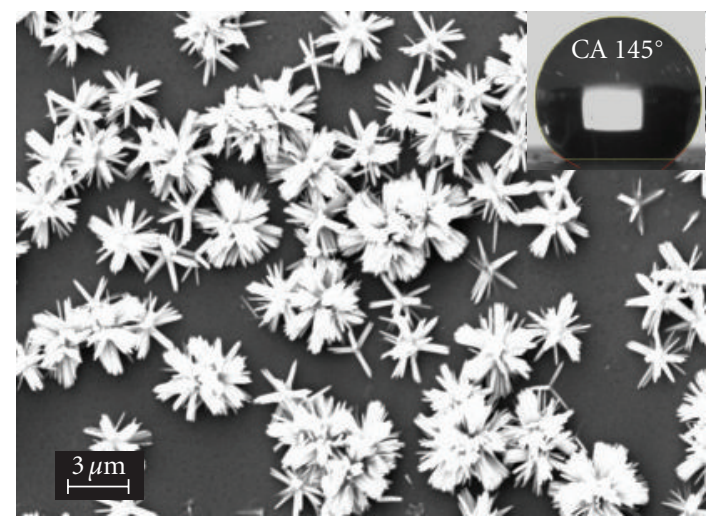

(a)

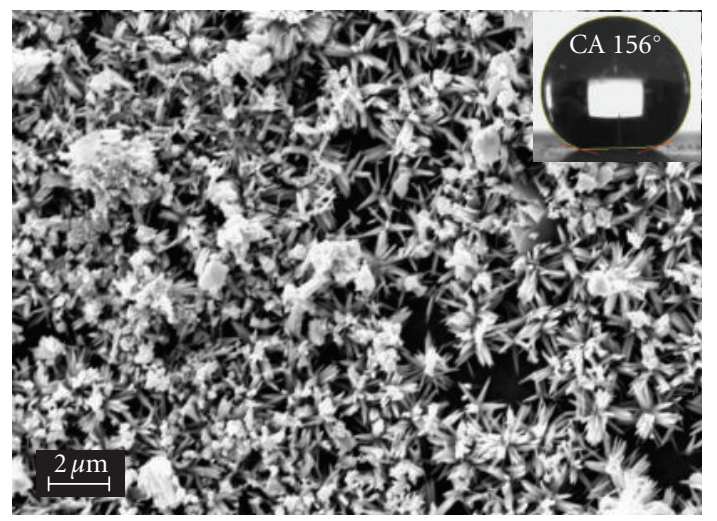

(b)

Figure 2: Surface morphology of $\mathrm{ZnO}$ coating immersed in stearic acid (a), $\mathrm{ZnO}$ heat treated at $70^{\circ} \mathrm{C}$ and immersed in stearic acid ( $\left.0.002 \mathrm{M}\right)$ (b). Insets show the profiles of the water droplet on the film surface.

the growth of the crystallites [9, 20]. Similar structure has been reported by Wang et al. for $\mathrm{ZnO}$ powder synthesized from $\mathrm{ZnSO}_{4}$ and $\mathrm{NaOH}$ solution [21]. However, Shinde et al. have reported a cone-like structure for $\mathrm{ZnO}$ deposited from an alkaline $\mathrm{Zn}\left(\mathrm{NO}_{3}\right)_{2}$ solution [4]. Thus, by varying the alkalinity of the solution, different morphologies can be obtained. Strong alkaline solution results in a structure comprising of discrete nanorods, while a weak alkaline solution produces an assembled nanorod structure [21]. Zhang et al. have also reported the influence of $\mathrm{pH}$ on the surface morphology and wettability [19].

$\mathrm{ZnO}$ is basically a highly hydrophilic material with WCA $<5^{\circ}$. After heat treatment at $350^{\circ} \mathrm{C}$ for $2 \mathrm{~h}$ and $4 \mathrm{~h}$, the $\mathrm{ZnO}$ coatings did not exhibit any change in their wetting behaviour and remained hydrophilic. Hence, their detailed characterization has not been discussed. However, Shinde et al. have reported that the $\mathrm{ZnO}$ coating annealed at $350^{\circ} \mathrm{C}$ for $2 \mathrm{~h}$ displayed superhydrophobic nature and its structure appeared as well-defined cones [4]. Thus, the wettability of solid surface is governed by both the chemical composition and the geometrical microstructure of the surface.
$\mathrm{ZnO}$ coatings were hydrophobically modified by immersing in varying concentrations of stearic acid for different durations of time, and their WCA values were measured. It was observed that the as-deposited $\mathrm{ZnO}$ coating after immersion in $0.01 \mathrm{M}$ stearic acid for 6 days displayed a WCA of $145^{\circ}$. The surface morphology and diffraction pattern of the coating modified with stearic acid was similar to that of the as-deposited $\mathrm{ZnO}$ coating. In order to render hydrophobicity to the coating, a prolonged immersion time of 6 days was required. On the other hand, if $\mathrm{ZnO}$ coating was heated to $70^{\circ} \mathrm{C}$ for $16 \mathrm{~h}$ and subsequently immersed in stearic acid, superhydrophobicity was achieved in much shorter immersion time. The heat-treated $\mathrm{ZnO}$ coating was immersed in stearic acid of different concentrations and for various time durations. It was found that a low concentration of $0.002 \mathrm{M}$ and short immersion time of 30 minutes was optimum to obtain superhydrophobicity. The morphology appears as sword-like nanorods with sharp tips, arranged in a flower-like arrangement (Figure 2(b)). In addition, cluster of flowers grouped over one another was also observed. EDX analysis revealed that the $\mathrm{Zn}$ content was slightly lower 


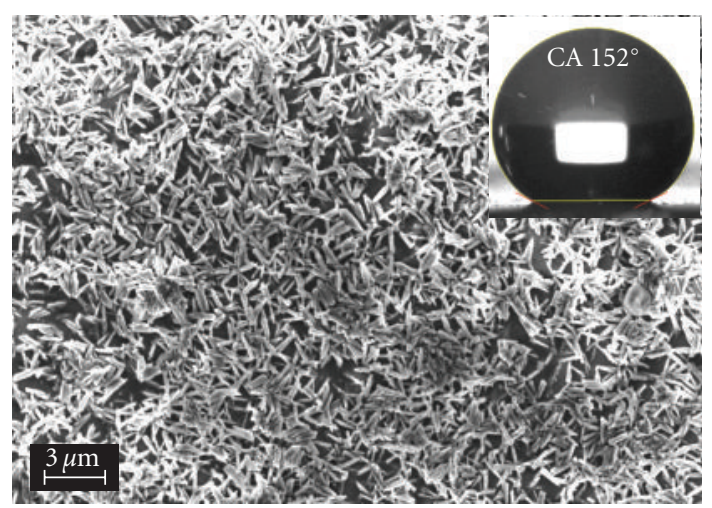

(a)

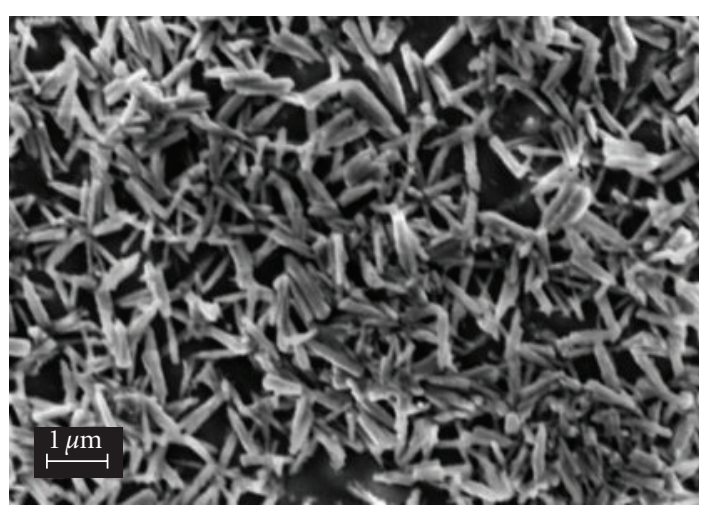

(b)

FIGURE 3: Surface morphology of $\mathrm{ZnO}$ coating treated with fluoroalkylsilane at 2500X (a) and 5000X (b). Inset shows the image of water drop on the film surface.

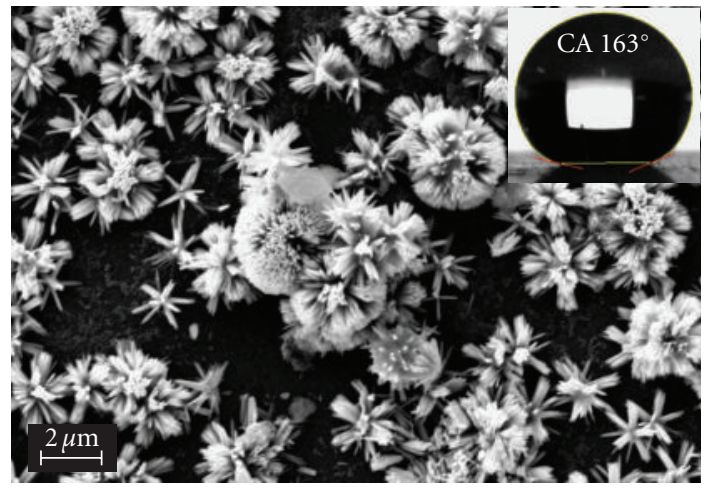

(a)

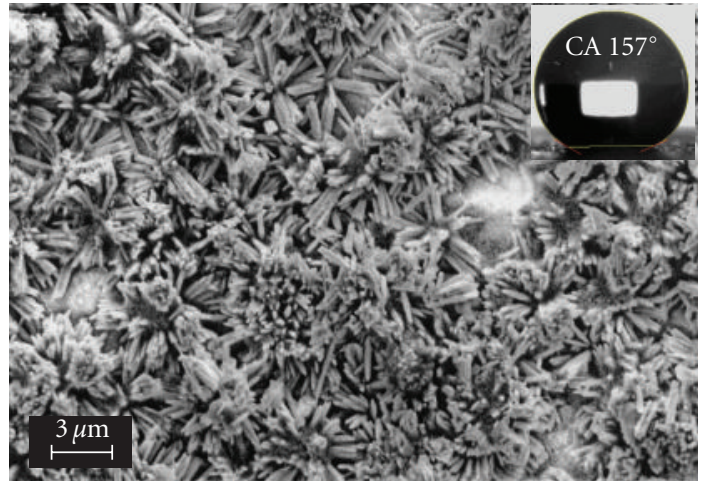

(b)

FIGURE 4: Surface morphology of ZnO-PTFE coating treated with stearic acid (a) and fluoroalkyl silane (b). Insets show the image of the water drop on the film surface.

on these clusters $(65 \mathrm{wt} \%)$ as compared to single flower $(72 \mathrm{wt} \%)$. Further, a marginal rise in carbon and oxygen content was observed on the floral cluster. This may be due to the contribution from the stearic acid. The X-ray diffractogram shows the presence of $\mathrm{ZnO}$ and $\mathrm{Zn}(\mathrm{OH})_{2}$ (Figure 1(b)). The effect of fluoroalkylsilane modification on the hydrophobic behaviour of $\mathrm{ZnO}$ was also studied. The morphology of fluoroalkylsilane-modified $\mathrm{ZnO}$ coating is depicted in Figure 3. The structure appears as discrete rods distributed uniformly throughout the surface. The X-ray diffraction studies showed the presence of only $\mathrm{Zn}(\mathrm{OH})_{2}$.

The wettability of the coatings is expressed as water contact angle, and this angle is inversely proportional to the wettability. Figure 2 shows the water drop profile for (a) alkanoic acid-modified coating, (b) heat-treated followed by alkanoic acid modification and Figure 3 shows the profile of fluoroalkylsilane-modified coating. As-deposited $\mathrm{ZnO}$ coating was observed to be hydrophobic, with a WCA of $120^{\circ}$. However, on immersion in $0.10 \mathrm{M}$ stearic acid, an improvement in the hydrophobic behaviour was observed with an enhancement in the contact angle values to $145^{\circ}$ (Figure 2(a)). However, a combined treatment of heating at $70^{\circ} \mathrm{C}$ and immersion in $0.002 \mathrm{M}$ stearic acid rendered the coating superhydrophobic. It exhibited a contact angle of $156^{\circ}$, and the shape of the water droplet is shown in Figure 2(b). The hydrophobicity imparted by stearic acid can also be attributed to the fact that stearic acid chemically bonded to the surface of $\mathrm{Zn}^{2+}$ ions leading to the $\mathrm{ZnO}$ surface being covered by a monolayer of organic molecules with their nonpolar tails exposed to air [9]. The fluoroalkylsilane modified $\mathrm{ZnO}$ coating also exhibited superhydrophobic behaviour with a moderate reduction in the contact angle values to $152^{\circ}$ (Figure 3 ). The higher contact angle $\left(156^{\circ}\right)$ of the coupled heat treatment and stearic acid modification of $\mathrm{ZnO}$ coating may be due to the less air entrapment in the clustered floral structure compared to the rod-like structure of silane-modified coating. Thus, different WCAs are due to the different surface structures. It can also be inferred that fluorosilane imparts higher degree of hydrophobicity $\left(152^{\circ}\right)$ due to its low surface free energy compared to exclusive alkanoic acid treatment $\left(145^{\circ}\right)$.

The above studies showed that superhydrophobic $\mathrm{ZnO}$ surface can be achieved, by heating for long hours (16 h) followed by short duration $(0.50 \mathrm{~h})$ immersion in stearic 
acid. Although the coating is superhydrophobic in nature, a long time was spent to attain this nonwetting property. Hence, an alternative $\mathrm{ZnO}$-PTFE composite coating was produced by solution immersion method.

3.2. Microstructure and Hydrophobicity of Modified $\mathrm{ZnO}$ PTFE Composite Coating. The ZnO-PTFE composite coating was developed in a similar manner as that of $\mathrm{ZnO}$ coating, and it was subsequently modified with stearic acid and fluorosilane. The surface morphology of the modified $\mathrm{ZnO}$ PTFE composite coatings is depicted in Figure 4. The surface morphology of stearic acid-modified ZnO-PTFE coating appears as floral structures along with a clustered growth (Figure 4(a)). The EDX studies showed that the clustered structure was rich in fluorine $(5 \mathrm{wt} \%$ on the cluster and $2 \mathrm{wt} \%$ on floral pattern) indicating that it was the contribution from PTFE. The X-ray diffraction studies revealed that the coating comprised of $\mathrm{ZnO}$ and $\mathrm{Zn}(\mathrm{OH})_{2}$. The silane-modified coating exhibited a structure comprising of compactly arranged rod-like structures distributed in a random manner (Figure 4(b)). The diffraction studies showed that the coating comprised of exclusively $\mathrm{Zn}(\mathrm{OH})_{2}$. It was seen from the wettability test that the contact angle for stearic acid-modified ZnO-PTFE coating is $163^{\circ}$ while that for silane-modified coating is $157^{\circ}$. The water drop profiles are depicted in Figure 4. Thus, it is observed that the incorporation of low surface energy PTFE in $\mathrm{ZnO}$ helped to improve the hydrophobicity without the necessity of heat treatment or long immersion time. It is also seen that unlike the modified $\mathrm{ZnO}$ coating wherein the fluorosilane imparted higher hydrophobicity compared to alkanoic acid, in the case of ZnO-PTFE coating the alkanoic acid imparted higher degree of hydrophobicity compared to fluorosilane. This may be due to the difference in the interaction of PTFE with stearic acid and fluoroalkylsilane. Thus, modified ZnO-PTFE composite helps to obtain a superhydrophobic surface in a simple manner. This can be associated with the interaction between fluorine, the most effective element for lowering the surface free energy, because of its small atomic radius and high electronegativity, and the roughness of the substrate induced by etching.

The superhydrophobic behaviour of modified $\mathrm{ZnO}$ films can be explained in terms of the Cassie-Baxter model [22]. According to Cassie-Baxter equation,

$$
\cos \theta_{\mathrm{C}}=f_{1}\left(\cos \theta_{1}+1\right)-1
$$

where $\theta_{\mathrm{C}}$ and $\theta_{1}$, respectively, are apparent WCA of the corresponding rough and smooth surfaces, $f_{1}$ is the surface area fraction of the solid. A water drop on the modified $\mathrm{ZnO}$ film only contacts the tips of the clusters and flowerlike structures on the rough surface resulting in a large water-air interface. Such composite surface prevents water droplets from penetrating into the cavities, leading to superhydrophobicity. However, in unmodified $\mathrm{ZnO}$ films, water penetrates into the gap between the clusters thereby displaying merely a hydrophobic behaviour.

\section{Conclusions}

$\mathrm{ZnO}$ being a widely adopted material to obtain superhydrophobic surface was deposited on glass substrate by immersion deposition method. Some of the modifications adopted by various investigators like alkanoic acid immersion, heat treatment, and fluoroalkylsilane modification were carried out for the $\mathrm{ZnO}$ coatings obtained in the present study. The observation made was that $\mathrm{ZnO}$ deposition followed by heat treatment at $70^{\circ} \mathrm{C}$ for 16 hours and immersion in a solution of stearic acid had resulted in a surface with the highest hydrophobicity $\left(\mathrm{CA} 156^{\circ}\right.$ ). The studies conducted also revealed that the modification of $\mathrm{ZnO}$ with fluoroalkylsilane imparted superhydrophobicity but to a lesser extent $\left(\mathrm{CA} 152^{\circ}\right)$. The prolonged heat treatment time $(16 \mathrm{~h})$ can be avoided by the incorporation of a low surface energy PTFE in the $\mathrm{ZnO}$ coating. The $\mathrm{ZnO}$-PTFE composite coatings on modification with either stearic acid or fluoroalkylsilane imparted greater superhydrophobicity compared to modified $\mathrm{ZnO}$ coatings. It was also seen that the surface morphology of the coating was greatly influenced by the nature of low energy material used for hydrophobic modification.

It was inferred from the morphology and contact angle measurement studies that the incorporation of PTFE in $\mathrm{ZnO}$ matrix followed by modification with stearic acid or fluoroalkylsilane produced a superhydrophobic surface in a simple and cost effective manner.

\section{Acknowledgments}

The authors would like to thank Dr. A. R. Upadhya, Director NAL, Dr. Kota Harinarayana, Raja Ramanna Fellow, NAL for their constant support and encouragement. They are grateful to Dr. Anjana Jain and Mr. Raghavendra for their technical assistance with XRD and SEM studies. The authors would also like to thank Ms. Nandita Ganesh for the assistance in carrying out the experiments.

\section{References}

[1] X. Zhang, F. Shi, J. Niu, Y. Jiang, and Z. Wang, "Superhydrophobic surfaces: from structural control to functional application," Journal of Materials Chemistry, vol. 18, no. 6, pp. 621-633, 2008.

[2] X. M. Li, D. Reinhoudt, and M. Crego-Calama, "What do we need for a superhydrophobic surface? A review on the recent progress in the preparation of superhydrophobic surfaces," Chemical Society Reviews, vol. 36, no. 8, pp. 1350-1368, 2007.

[3] I. Perelshtein, G. Applerot, N. Perkas et al., "Antibacterial properties of an in situ generated and simultaneously deposited nanocrystalline $\mathrm{ZnO}$ on fabrics," ACS Applied Materials \& Interfaces, vol. 1, no. 2, pp. 361-366, 2009.

[4] V. R. Shinde, C. D. Lokhande, R. S. Mane, and S.-H. Han, "Hydrophobic and textured $\mathrm{ZnO}$ films deposited by chemical bath deposition: annealing effect," Applied Surface Science, vol. 245, no. 1-4, pp. 407-413, 2005.

[5] T. A. Vijayan, R. Chandramohan, S. Valanarasu, J. Thirumalai, and S. P. Subramanian, "Comparative investigation on nanocrystal structure, optical, and electrical properties of $\mathrm{ZnO}$ 
and Sr-doped $\mathrm{ZnO}$ thin films using chemical bath deposition method," Journal of Materials Science, vol. 43, no. 6, pp. 17761782, 2008.

[6] N. Saleema and M. Farzaneh, "Thermal effect on superhydrophobic performance of stearic acid modified $\mathrm{ZnO}$ nanotowers," Applied Surface Science, vol. 254, no. 9, pp. 26902695, 2008.

[7] D. Li, Z. T. Liu, YU. H. Leung, A. B. Djurisic, M. H. Xie, and W. K. Chan, "Transition metal-doped $\mathrm{ZnO}$ nanorods synthesized by chemical methods," Journal of Physics and Chemistry of Solids, vol. 69, no. 2-3, pp. 616-619, 2008.

[8] S. Yin and T. Sato, "Mild solution synthesis of zinc oxide films with superhydrophobicity and superhydrophilicity," Journal of Materials Chemistry, vol. 15, no. 43, pp. 4584-4587, 2005.

[9] X. Wu, L. Zheng, and D. Wu, "Fabrication of superhydrophobic surfaces from microstructured $\mathrm{ZnO}$-based surfaces via a wet-chemical route," Langmuir, vol. 21, no. 7, pp. 2665-2667, 2005.

[10] Y. Masuda and K. Kato, "Morphology control of zinc oxide particles at low temperature," Crystal Growth and Design, vol. 8, no. 8, pp. 2633-2637, 2008.

[11] K. E. Yu, Z. Jin, X. Liu, Z. Liu, and Y. Fu, "Synthesis of size-tunable $\mathrm{ZnO}$ nanorod arrays from $\mathrm{NH}_{3} \cdot \mathrm{H}_{2} \mathrm{O} / \mathrm{ZnNO}_{3}$ solutions," Materials Letters, vol. 61, no. 13, pp. 2775-2778, 2007.

[12] Z. Wang, M. Wang, Z. Lin, Y. Xue, G. E. Huang, and X. I. Yao, "Growth and interconversion of $\mathrm{ZnO}$ nanostructure films on different substrates," Applied Surface Science, vol. 255, no. 9, pp. 4705-4710, 2009.

[13] Q. I. Wang, B. Zhang, M. Qu, J. Zhang, and D. He, "Fabrication of superhydrophobic surfaces on engineering material surfaces with stearic acid," Applied Surface Science, vol. 254, no. 7, pp. 2009-2012, 2008.

[14] E. Hosono, S. Fujihara, I. Honma, and H. Zhou, "Superhydrophobic perpendicular nanopin film by the bottom-up process," Journal of the American Chemical Society, vol. 127, no. 39, pp. 13458-13459, 2005.

[15] A. Safaee, D. K. Sarkar, and M. Farzaneh, "Superhydrophobic properties of silver-coated films on copper surface by galvanic exchange reaction," Applied Surface Science, vol. 254, no. 8, pp. 2493-2498, 2008.

[16] M. Qu, B. Zhang, S. Song, L. Chen, J. Zhang, and X. Cao, "Fabrication of superhydrophobic surfaces on engineering materials by a solution-immersion process," Advanced Functional Materials, vol. 17, no. 4, pp. 593-596, 2007.

[17] M. Li, J. Xu, and Q. Lu, "Creating superhydrophobic surfaces with flowery structures on nickel substrates through a wetchemical-process," Journal of Materials Chemistry, vol. 17, no. 45, pp. 4772-4776, 2007.

[18] H. Y. Kwong, M. H. Wong, Y. W. Wong, and K. H. Wong, "Superhydrophobicity of polytetrafluoroethylene thin film fabricated by pulsed laser deposition," Applied Surface Science, vol. 253, no. 22, pp. 8841-8845, 2007.

[19] J. Zhang, W. Huang, and Y. Han, "Wettability of zinc oxide surfaces with controllable structures," Langmuir, vol. 22, no. 7, pp. 2946-2950, 2006.

[20] R. Saravana Kumar, P. Sudhagar, R. Sathyamoorthy, P. Matheswaran, and Y. S. Kang, "Direct assembly of $\mathrm{ZnO}$ nanostructures on glass substrates by chemical bath deposition through precipitation method," Superlattices and Microstructures, vol. 46, no. 6, pp. 917-924, 2009.
[21] Y. Wang, X. Li, N. Wang, X. Quan, and Y. Chen, "Controllable synthesis of $\mathrm{ZnO}$ nanoflowers and their morphologydependent photocatalytic activities," Separation and Purification Technology, vol. 62, no. 3, pp. 727-732, 2008.

[22] A. B. D. Cassie and S. Baxter, "Wettability of porous surfaces," Transactions of the Faraday Society, vol. 40, pp. 546-551, 1944. 

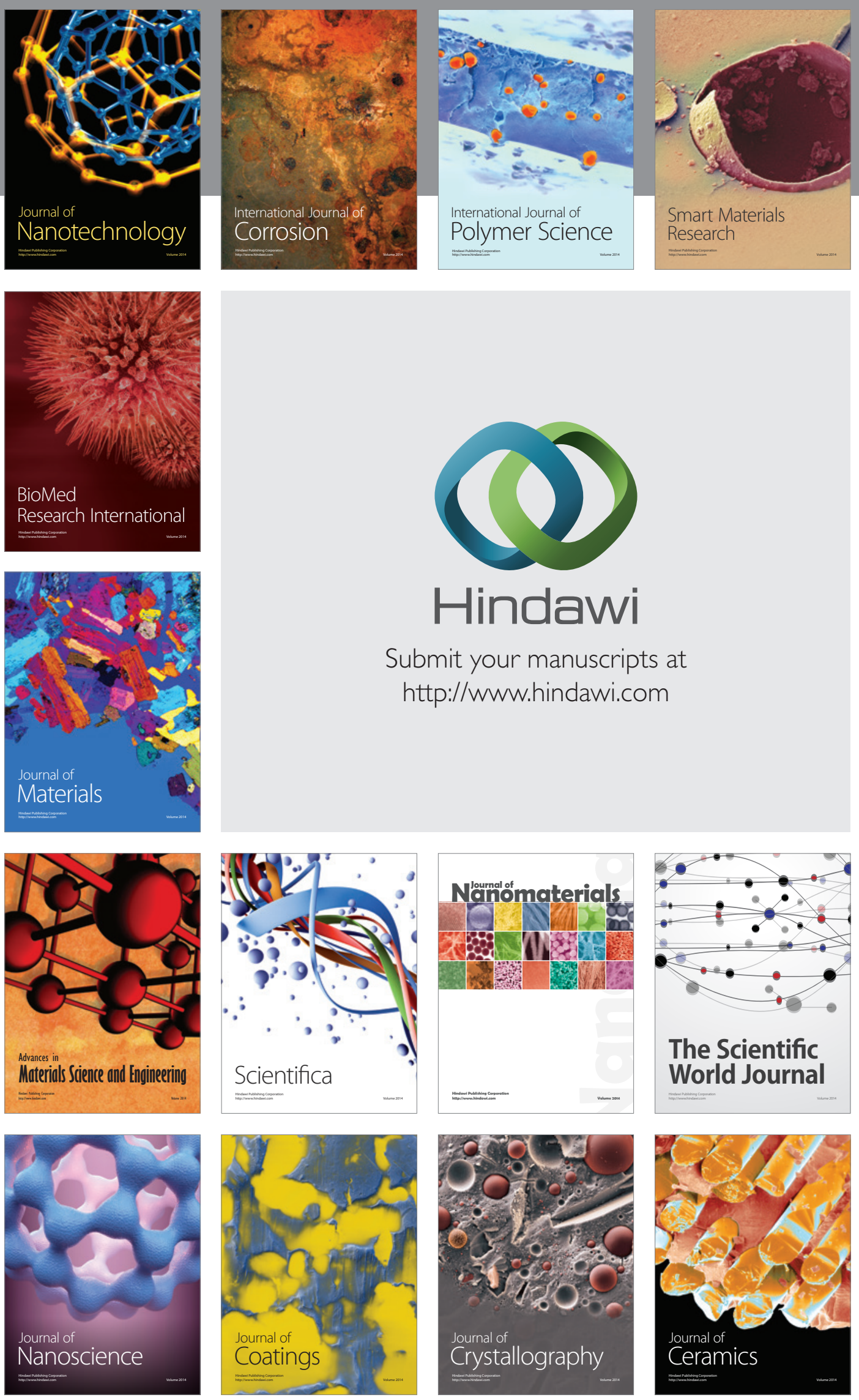

The Scientific World Journal

Submit your manuscripts at

http://www.hindawi.com

\section{World Journal}

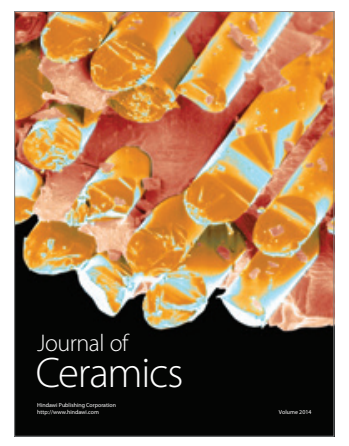

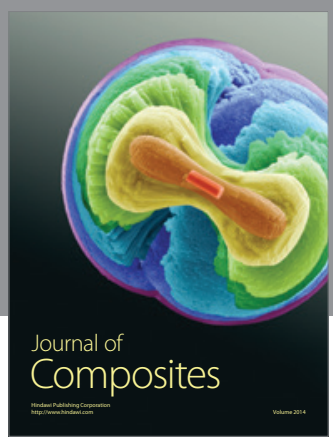
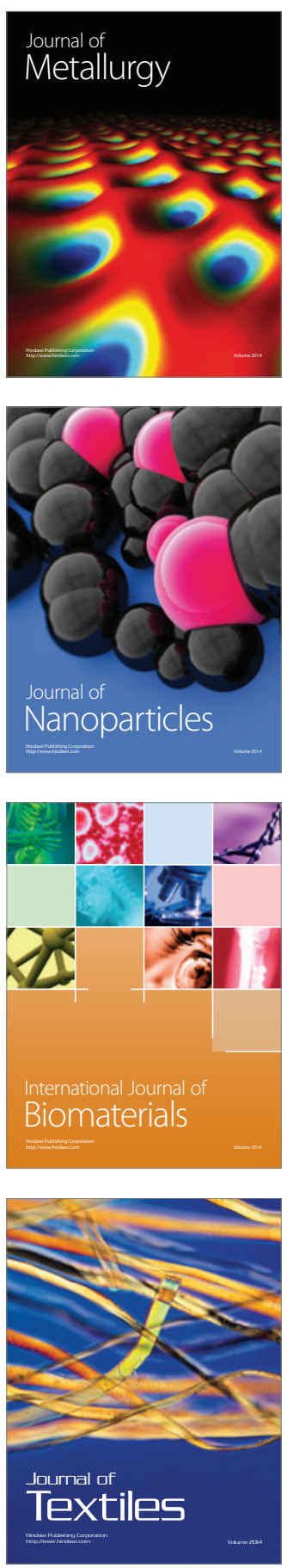